\title{
The GM Contamination Register: a review of recorded contamination incidents associated with genetically modified organisms (GMOs), 1997-2013
}

Becky Price ${ }^{1}$ and Janet Cotter $^{2^{*}}$

\begin{abstract}
Background: Since large-scale commercial planting of genetically modified (GM) crops began in 1996, a concern has been that non-GM crops may become contaminated by GM crops and that wild or weedy relatives of GM crops growing outside of cultivated areas could become contaminated. The GM Contamination Register contains records of GM contamination incidents since 1997 and forms a unique database. By the end of 2013, 396 incidents across 63 countries had been recorded.
\end{abstract}

Results: Analysis of the Register database reveals rice has the highest number of GM contamination incidents of all crops (accounting for a third of incidents), despite there being no commercial growing of GM rice anywhere in the world. The majority of these incidents derive from two distinct cases of contamination of unauthorised GM rice lines, LLRICE from the USA and BT63 rice from China. Maize accounts for 25\% of GM contamination incidents, whilst soya and oilseed rape account for approximately $10 \%$ of incidents. Although factors such as acreage grown, plant biology, designation as a food or non food crop and degree of international trading can potentially affect the frequency and extent of contamination, it is not possible to determine which are dominant.

The Register records a total of nine cases of contamination from unauthorised GM lines, i.e. those at the research and development stage with no authorisation for commercial cultivation anywhere in the world. An important conclusion of this work is that GM contamination can occur independently of commercialisation. Some of these cases, notably papaya in Thailand, maize in Mexico and grass in USA have continued over a number of years and are ongoing, whilst other contamination cases such as Bt10 maize and pharmaceutical-producing GM crops occur only with a single year. The route(s) of contamination are often unclear.

Conclusions: The detection of GMO contamination is dependent on both routine and targeted monitoring regimes, which appears to be inconsistent from country to country, even within the EU. The lack of an analytical methodology for the detection of GM crops at the field trial stage (i.e. pre-commercialisation) can hamper efforts to detect any contamination arising from such GM lines.

Keywords: Genetically modified; Contamination; Gene flow; Crops; Food; Feed; Field trial

\footnotetext{
* Correspondence: janet.cotter@greenpeace.org

${ }^{2}$ Greenpeace Resaerch Laboratories, Innovation Centre Phase 2, University of Exeter, Exeter EX4 4RN, UK

Full list of author information is available at the end of the article
} 


\section{Background}

Large scale commercial planting of genetically modified (GM) crops began in 1996. Alongside concerns regarding the long term health, environmental and socioeconomic impacts of these crops, a specific concern has been that of contamination of non-GM crops by GM crops and also of relatives established outside planted areas. Concerns regarding GM contamination of nonGM crops include loss of markets, particularly those requiring "GM-free" products; future supply of non-GM seed (especially for seed saved from open pollinated crops) and possible introgression (spreading) of the GM trait into both wild and feral populations of crop relatives (Marvier and van Acker 2005; Mellon and Rissler 2004; Bauer-Panskus et al. 2013).

Contamination of non-GM crops by GM crops has occurred, and there are several well-documented cases, e.g. Starlink corn (Fox 2001), Liberty Link rice (LLRICE; US Food and Drug Administration 2006). Reviews of GM contamination by Marvier and van Acker (2005) and Bauer-Panskus et al. (2013) considered that there are many factors contributing to the likelihood of GM contamination, and that containment of any contamination can be problematic, even unlikely. For example, Marvier and van Acker (2005) considered of the movement of transgenes a virtual certainty via routes such as gene flow during cultivation, reintroduction of transgenes from volunteer and feral crop populations, seed transport (including between continents) and human error such as co-mingling of seed. Bauer-Panskus et al. (2013) considered that domestication and ease of hybridization with wild or weedy relatives important factors. Possible environmental consequences of introgression of transgenes into wild or feral population include increased invasiveness as a result of a fitness enhancing trait such as insect resistance (Snow et al. 2003; Samuels 2013), reduced capacity for co-existence of GM and non-GM crops (Marvier and van Acker 2005) and hampering future breeding efforts (Bauer-Panskus et al. 2013). However, Ellstrand (2012) found that transgene escape to wild varieties was rare, but that transgenes tended rather to move into other varieties of the same species.

The United Nations (UN) Cartagena Protocol on Biosafety to the Convention on Biological Diversity partly addresses the control of living genetically modified organisms (GMOs) (termed living modified organisms within the convention), covering seeds (UN Cartagena Protocol on Biosafety 2014). In 2002, this established an advance informed agreement procedure meaning that only those living GMOs (primarily seeds) with formal approval from the receiving country's national body can be imported. In addition to the UN Cartagena Protocol, many governments around the world, including the European Union (EU), have established national regulatory regimes that issue formal authorisation (or, in the USA, deregulation) for any deliberate release of GMOs into the environment (i.e. outside of laboratory containment) and marketing as seed, human food and animal feed products. Specific GMOS may be authorised either as experimental field trials (e.g. for testing of agronomic traits), for commercial cultivation and for marketing as human food and/ or animal feed. Authorisations can be granted for a GMO to be marketed without cultivation, e.g. if the GMO is to be imported into a country, but not grown. Databases of authorisations for the cultivation and marketing of GMOs are available both globally (Center for Environmental Risk Assessment 2014) and also for certain regions such as the EU (EC 2014a). In contrast, databases for experimental field trials of GMOs are held by national or regional authorities, e.g. for the USA (Information Systems for Biotechnology 2014), Australia (Office of the Gene Technology Regulator 2014), the European Union (EC 2014b). In many countries, such databases do not exist, or are not publically available.

The presence of globally unauthorised GMOs (i.e. those without any authorisation for cultivation or marketing anywhere in the world) and unapproved GMO crops (i.e. those without authorisation for cultivation and/or marketing in that country or region) in food/feed or seed can be grounds for either product recalls or rejection of imports at national borders. Where labelling of GMO ingredients is mandatory (e.g. the EU for food/ feed), the presence of GMO ingredients in unlabelled foodstuffs above a prescribed threshold $(0.9 \%$ for the $\mathrm{EU}$, EC 2003) is also grounds for either rejection of imports or product withdrawal. Labelling is not required for GM non food products (e.g. biofuels or materials such as cotton) in the EU (EC 2003). Global organic farming standards require that both seed and food are free from GMOs (International Foundation for Organic Agriculture Movements 2002) and many national organic farming bodies have defined thresholds of the maximum permitted adventitious GMO content (usually between $0.1 \%$ and $0.9 \%$ ). The presence of GMOs above permitted thresholds can result in loss of organic certification.

Methodologies for the detection of GMOs fall into two broad categories: protein-based methods which target the novel protein(s) produced by the GMO and deoxyribonucleic acid (DNA)-based methods which target the inserted genetic construct(s). Protein-based methods typically employ an enzyme-linked immunosorbent assay (ELISA). Commercially-available ELISA kits comprise either qualitative immunochromotographic (lateral flow) strips, which can be used both in the field and laboratory, or well plates enabling quantitative analysis. In contrast, DNA-based methods utilise polymerase chain reaction (PCR) and require a specialised laboratory set up. The EC Joint Research Centre (JRC) has developed 
and validated methods for the detection and quantification of individual GMO events (EC JRC 2010, 2014a) and run international collaborative programmes, predominantly with governmental laboratories, to increase harmonisation and standardisation of methodologies for analysing GMOs (EC JRC 2014b). In practice, proteinbased methods (especially qualitative assays) tend to be used to screen for the presence of GMOs (Ermolli et al. 2006), whilst DNA-based methods offer more robust analysis (Miraglia et al. 2004).

Despite the concerns regarding GM contamination, there is no systematic global monitoring or recording of GM contamination incidents. In the EU region, however, recording of GM contamination incidents in food/feed products is afforded by the European Commission (EC) Rapid Alert System on Food and Feed (RASFF) (EC RASFF 2014). RASFF members consist of the European Union countries together with Iceland, Liechtenstein, Norway and Switzerland. To date, the RASFF provides the most comprehensive data set of GM contamination in food/feed provided by a national or regional regulatory body. Along with other food contaminants, the RASFF records positive results on its website (EC RASFF 2014) for unapproved GM ingredients in food/ feed products both from within the EU region and imports into the EU region. Outwith the RASFF, individual incidents of GM contamination are generally reported via national governments, non governmental organisations (NGOs) and/or the media.

In the absence of global systematic monitoring of GM contamination incidents, GeneWatch UK and Greenpeace International established the GM Contamination Register (hereafter termed "The Register") to record these incidents. The website (GM Contamination Register 2014) is a searchable database used by individuals, public interest groups and governments. It is recognised by the UN Biosafety Clearing-House, an information exchange facility for the Cartagena Protocol. The Register now holds a database of recorded incidents of GM contamination over 17 years, from 1997 to the present time. This paper presents an analysis of the recorded incidents from 1997 to the end of 2013. We investigate the frequency of GM contamination incidents over this period, the principal crops and countries associated with these incidents and focus on contamination arising from unauthorised GM crops. Finally, we investigate the contribution of the contribution of analytical methodologies and monitoring regimes to the detection of GM contamination incidents.

\section{Methodology}

The GM Contamination Register is based on individual incidents reported by governmental and inter-governmental authorities, non governmental organisations (NGO)s and/ or the media. Monitoring English speaking media, science journals and internet-based news groups provides alerts to these incidents. Organisations testing for the presence of GMOs (such as NGOs) are invited to send their results to the Register. Coverage is global, and GM animals and plants are included. GM microbes are not excluded, although there have been no recorded incidences of contamination by these organisms to date. The Register commenced in 2005, was backdated to 1997. The Register is still active although only those incidents recorded to the end of 2013 are included here.

Each report of a contamination incident is evaluated for its dependability. The Register includes only incidents where the contamination can be verified to a reasonable degree of certainty. That is, either an announcement by a producer of a GM crop, a governmental body or from an NGO based on the identification of the GM crop resulting from PCR analysis. The PCR methodologies need to be accredited to the International Organization for Standardization (ISO), i.e. ISO standard 17025 (ISO 2005) and this usually entails contracting analysis to a commercial or governmental laboratory. GM contamination incidents based on protein testing are excluded from the Register. Incidents reported via the RASFF are regarded as verified as they originate from government bodies. Similarly, those published in peer reviewed journals are also regarded as verified. Where the incident is announced by an NGO, copies of PCR results are requested as verification.

Where an incident cannot be verified from original or governmental sources, it is accepted for the Register if the reportage is via a reputable newspaper or news agency, preferably an international agency such as Reuters or Agence France-Presse. Such cases are reviewed after one year and internet searches are made for further evidence. In cases where the contamination findings are refuted or reasonable doubt cast on them, the incident is removed from the Register until any new evidence emerges.

For inclusion in the GM Contamination Register, incidents must meet at least one of the following criteria:

- a breach of national or international law; sale of food/feed derived from GMOs that does not comply with regional or national labelling regulations,

- presence of unauthorised or unapproved GMO traits in crops and/or seed batches or, for approved GMO traits, presence above applicable thresholds,

- illegal plantings of GMOs or unauthorised releases to the environment or food/feed chain.

- establishment of feral population(s) of a GM crop or presence of the genetic insert within wild or feral populations, including wild or weedy relatives.

If a GM incident has been verified and fulfils one of the criteria, brief details of the contamination incident 
(generally what, where, when and, if known, the source and route of contamination) are entered into the database. Only incidents that have been publicly documented are recorded on the Register. The Register does not, and cannot, record incidents that remain undetected. Therefore, those reported here represent the minimum number of GM contamination incidents.

The nature of GM contamination is such that once a single contamination incident has been identified, testing and monitoring can quickly result in the identification of several more contamination incidents involving the same GM line, often within the same month or year. In addition, international trading of agricultural commodities can result in repeated findings of contamination by the same GM line in many countries within the same year. These are termed 'repeated contamination' incidents and could skew the Register towards particular GM lines that are frequently tested for, or countries that conduct more thorough monitoring. To avoid this, the Register only records a new incident each time a GM line is found to be present within a country in a particular year. If the same GM line repeatedly contaminates within the same country and in the same year, no new incident is recorded and details are added to the existing incident instead. This enables the Register to indicate the extent of spread, both geographically and over time, of any given contamination episode whilst minimising any skew towards repeated contamination incidents.

\section{Results and Discussion}

As of 31 December 2013, the Register had recorded 396 incidents since 1997 (i.e. over a period of 17 years) and across 63 different countries (Additional file 1). Since 2000, there have been more than 10 incidents per year and, since 2005, more than 20 incidents per year (Figure 1). For 2006, there is a sharp spike in the number of incidents to nearly
60. This spike primarily relates to the discovery and spread of GM rice from the USA, which accounted for 28 incidents that year.

\section{GM contamination incidents by country}

The distribution of the total number of GM contamination incidents over the 17 year period by country displays an exponential decay type of pattern with a sharp initial decrease from the highest number of incidents per country and a long tail of countries with a much lower number of incidents (Figure 2). 50\% of the total number of incidents are accounted for by 11 countries, each with more than 12 incidents. This group is dominated by RASFF countries, together with North America and Australia. In contrast, 28 countries (just under half the total number of countries) with 3 or less reported incidents account for just under $10 \%$ (9.1\%). The remainder of the RASFF countries, several Asian countries, South Korea, China and Mexico recorded between 3 and 12 incidents per country.

The 4 countries reporting the highest number of incidents were Germany, USA, France and United Kingdom, three of which contribute to the RASFF. Together, these countries make up $27 \%$ of the total number contamination incidents. This does not correspond to the countries with the highest acreage of GM crops, which are USA, Brazil, Argentina and Canada (International Service for the Acquisition of Agri-biotech Applications 2013).

The RASFF database accounts for a significant number of incidents in the Register, approximately 60\% (244 out of 396) (Figure 3). The importance of recording repeated contamination events associated with the same GM line, within the same year and same country as one incident is illustrated by RASFF. If each notification for RASFF were included on the Register, they would account for nearly $80 \%$ of the total number of incidents (585 out of 736), dominating the Register and producing a skew

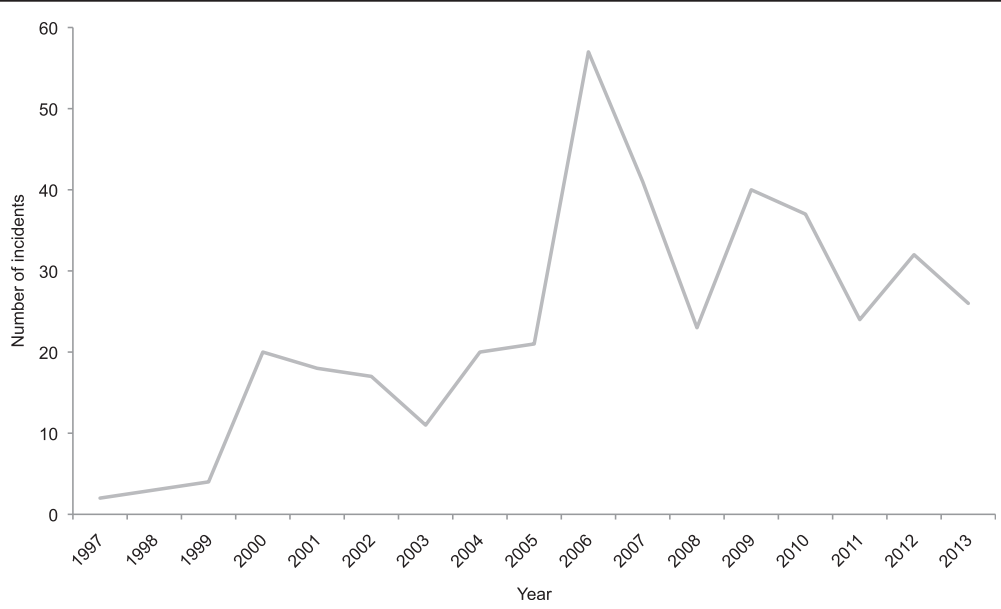

Figure 1 Total number of incidents recorded on the GM Contamination Register for all countries per year, 1997-2013. 


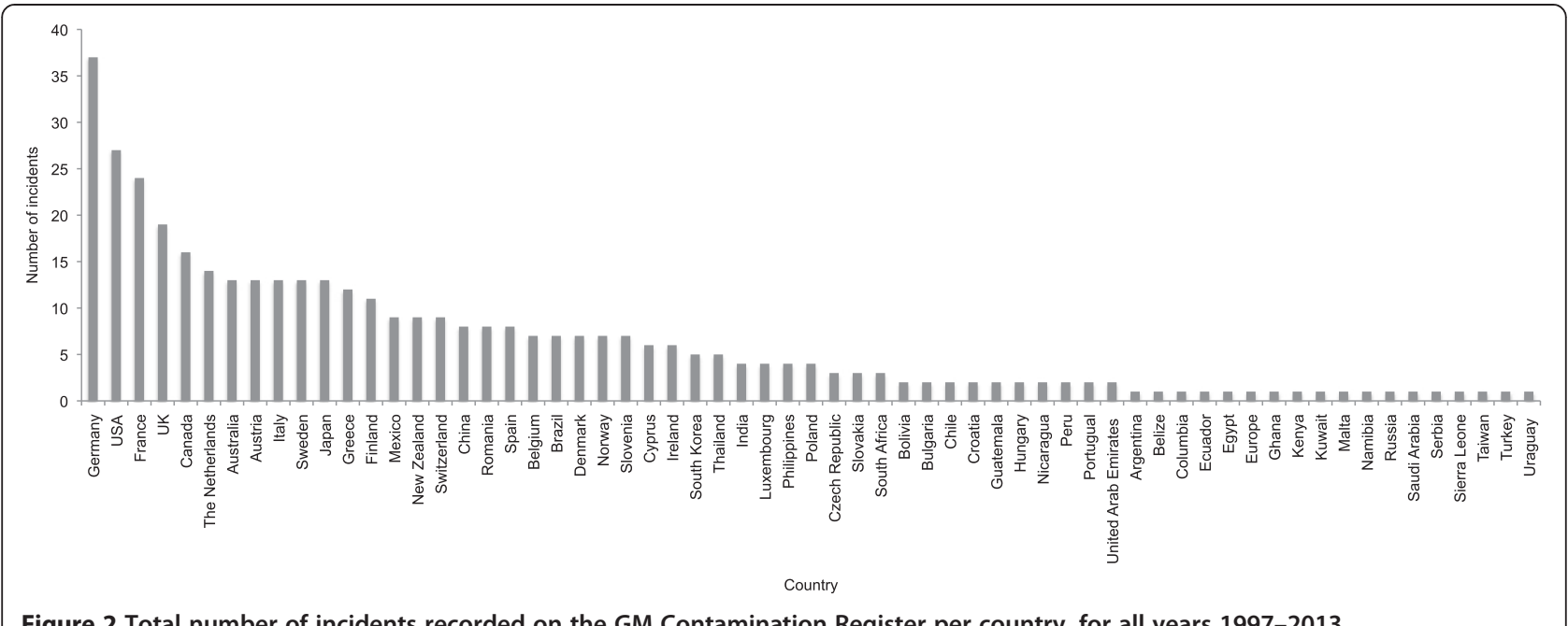

towards these repeated contamination events. The prominence of GM contamination incidents recorded for the EU via RASFF does not necessarily reflect a higher degree of GM contamination. It is more likely that there is routine monitoring and a mechanism for reporting such incidents.

\section{GM contamination by crop}

Rice is associated with the highest number of GM contamination incidents of all crops (Table 1), accounting for about a third of the total number of incidents. This is despite a global absence of any commercial cultivation of GM rice. There is a sharp peak in the number of incidents of GM rice contamination for 2006/7 (Figure 4).
The majority of these incidents derive from two distinct cases of contamination from unauthorised GMOs, one in the USA (LLRICE) and one in China (Bt63) and are further discussed in the section on globally unauthorised GM crops below. GM maize gives rise to the second most number of contamination incidents, accounting for a quarter of incidents (Table 1) with consistent contamination of between 5 and 10 incidents per year since 1999 (Figure 4). Soya and oilseed rape (canola) are the next most frequently associated with GM contamination, each accounting for approximately $10 \%$ of incidents (Table 1) with between 0 and 10 incidents per year (Figure 4).

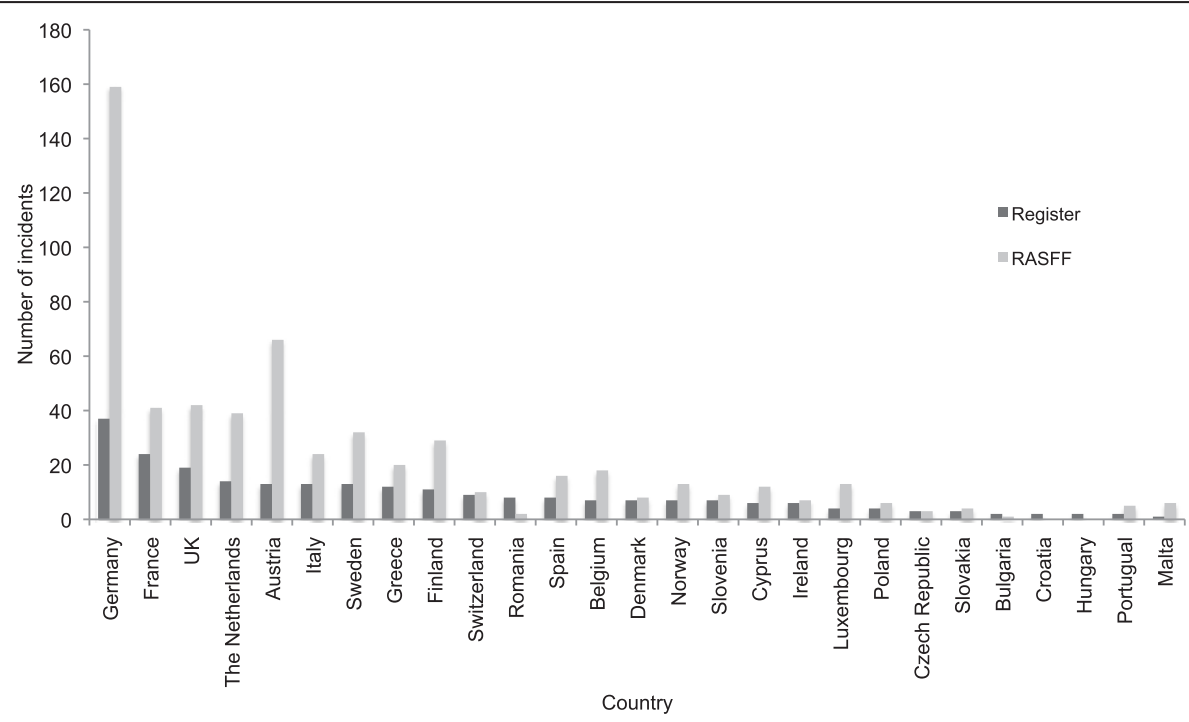

Figure 3 Comparison of GM Contamination Register with the EC RASFF database by country, for all years 1997-2013. EC RASFF database records notifications for each incident, including those relating to a single GM line in the same country and year. In the GM Contamination Register, these are recorded as a single incident, resulting is a lower total no. of incidents for each RASFF country. This prevents a skew of the data towards RASFF countries and the reportage of repeated incidents. 
Table 1 Total number of incidents recorded on the GM Contamination Register for each crop for all countries and all years, 1997-2013

\begin{tabular}{lll}
\hline Crop & No. of incidents & \% Total no. of incidents \\
\hline Rice & 134 & 34 \\
Maize & 98 & 25 \\
Oilseed rape/canola & 40 & 10 \\
Soybean & 37 & 9 \\
Flax & 26 & 6.5 \\
Papaya & 18 & 4.5 \\
Cotton & 14 & 3.5 \\
Fish & 5 & 1.3 \\
Grass & 4 & 1 \\
Pigs & 4 & 1 \\
Sugar beet & 4 & 1 \\
Arabidopsis thaliana & 3 & 0.75 \\
Potato & 2 & 0.5 \\
Alfalfa & 1 & 0.25 \\
Plum & 1 & 0.25 \\
Tomato & 1 & 0.25 \\
Wheat & 1 & 0.25 \\
Zucchini & 1 & 0.25 \\
Pollen in honey* & 1 & 0.25 \\
Cherry, kiwi \& olive trees** & 1 & 0.25 \\
Total & 396 & \\
\hline & & 1
\end{tabular}

*Pollen from GM corn, oil seed rape \& soya was found in honey imported into Switzerland (Greenpeace 2009).

**Experimental field trials of these GM trees exceeded the length of permit in Italy and are recorded together as one incident (Genetic Rights

Foundation 2012)

The acreage of a GM crop has potential to influence the number of contamination incidents because it could increase the opportunities for cross-pollination and comingling with non-GM seed/grain. International trading of a crop could also affect the number of incidents as many reported GM contamination incidents originate from national border checks. Maize, soya and oilseed rape are all major commodity crops and also the principal GM feed/food crops that are commercially grown. GM varieties are widely grown in many countries where they are authorised for cultivation. For example, in the USA, where GM crops were first cultivated, GM crop acreage accounted for $93 \%$ of all soya and $90 \%$ of corn in 2013 (USDA Economic Research Service 2014). A pilot study in the US found that DNA derived from GM crops was found in 50\% of non-GM varieties of corn and soy, and $83 \%$ of non-GM oilseed rape (Mellon and Rissler 2004). Although these findings are not regarded as contamination because no regulations have been infringed, it demonstrates that GMO traits are widespread in the USA. These GMO traits can enter into non-GM crops destined for export to countries/regions where they may not be approved or require labelling (e.g. the $\mathrm{EU})$. GM cotton was also widely grown in the USA in 2013 , accounting for $90 \%$ of the crop acreage but only accounting for $<4 \%$ of contamination incidents. This may be because it is a non food crop, and therefore not subject to labelling in the EU or inclusion in the RASFF. In contrast, the acreage of GM rice grown is extremely small, amounting only to field trials. However, rice is a highly traded commodity crop, with approximately 1.2 million tonnes imported into the EU during 2012/3 (EC 2013). In addition, there has been specific monitoring for unauthorised GM varieties in many countries post 2006, when the unauthorised cases of contamination were discovered. These two factors could have contributed to the high number of contamination incidents associated with GM rice, despite the global absence of commercial growing.

Plant biology, and specifically the tendency to outcross, is a factor that could affect the number of GM contamination incidents. GM maize is reported as "medium to high" risk and oilseed rape as "high" risk for pollen mediated gene flow (Eastham and Sweet 2002) and this may also contribute to the high number of

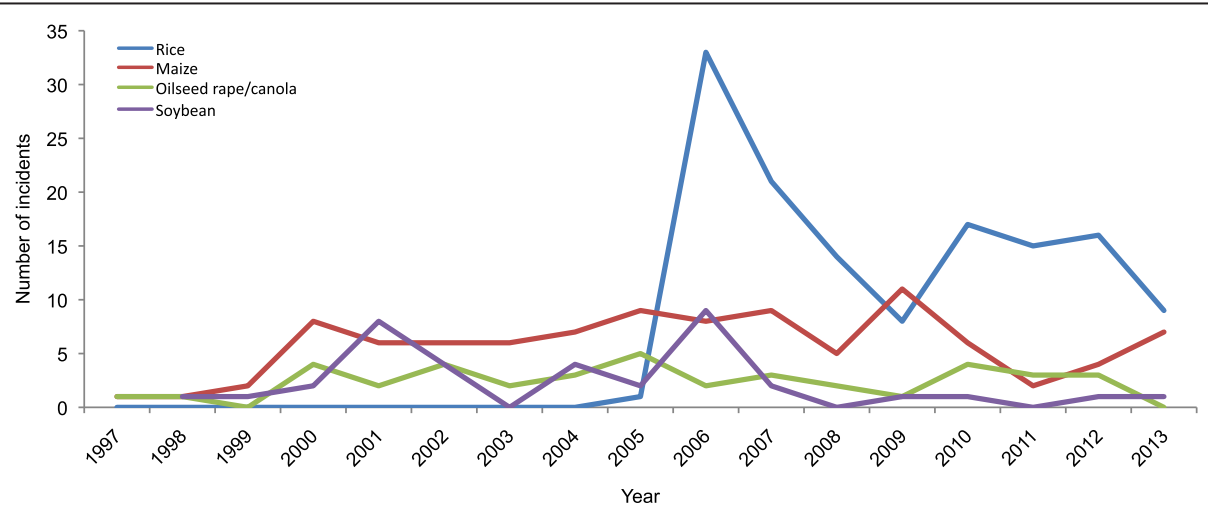

Figure 4 Incidents of GM contamination for rice, maize, oilseed rape (canola) and soya for all countries per year, 1997-2013. 
incidents reported for these two crops, but wouldn't be a strong factor for cotton and soya. Gene flow from GM rice, despite being regarded as a largely self pollinating crop, has been recorded, albeit at low levels and over short distances (Rong et al. 2007). Although factors such as acreage grown, plant biology, designation as a food or non food crop and degree of international trading can affect the number of contamination incidents recorded, it is not possible to determine from these data which are dominant. Indeed, for rice, the specific monitoring for unauthorised varieties of GM rice may to be an additional factor.

For maize and canola, there has been much international interest in specific cases of GM contamination, notably those associated with Starlink maize, maize in Mexico and establishment of feral GM oilseed rape populations. GM Starlink maize was only authorised for use in animal feed in 1998 (Bucchini and Goldman 2002, US Environmental Protection Agency 2008) but was found in USA food products intended for human consumption in 2000 by a coalition of non governmental groups (Fox 2001). The contamination persisted in the US at least until 2003, despite efforts to recover Starlink seed (Marvier and van Acker 2005). Starlink maize was the first contamination case with international ramifications. Contamination incidents were reported in 6 further countries (Bolivia, Canada, Egypt, Guatemala, Japan and South Korea) during both 2000 and 2001. Starlink was also reported in food aid to Bolivia in 2004 (Meridian Institute 2002) and present in foods in Saudi Arabia in 2009 and 2010 (Elsanhoty et al. 2013).

In Mexico, GM contamination of open-pollinated traditional varieties or landraces of maize was initially reported in a highly controversial publication in 2001 (Quist and Chapela 2001). The contamination was thought to originate from imports of GM maize from North America. The GM contamination was not detected in a 2003/4 study (Ortiz-Garcia et al. 2005) but later studies (PiñeyroNelson et al. 2009; Dyer et al. 2009) did find GM contamination of landraces. It is now generally accepted that GM transgenes are present in at least some maize landraces in Mexico (Dalton 2008, Snow 2009).

The establishment of feral populations of GM oilseed rape in both Canada and Japan has recently been reviewed in-depth by Bauer-Panskus et al. (2013). They describe that, in Canada, two types of feral GM oilseed rape populations conferring tolerance to two different herbicides, glufosinate ammonium (trade name: Liberty or Basta) and glyphosate (trade name: Roundup) occur in provinces where they are widely grown, or through which the grain is transported. In places, these have hybridized to be tolerant to both herbicides. In Japan, cultivation of GM oilseed rape is minor, but much oilseed rape is imported from Canada. Feral populations of GM oilseed rape tolerant to glufosinate, glyphosate or both have been reported in and around Japanese ports.

\section{Globally Unauthorised GMOs}

Several of the GM contamination incidents recorded on the Register are associated with "unauthorised" GM lines. That is, lines that were not authorised for commercial cultivation or marketing anywhere in the world at the time of the contamination incident but were experimental, or in development. Thus, risk assessments for food/feed and environmental safety have generally not been performed. Contamination incidents involving unauthorised GM lines tend to have a higher media profile than incidents originating from approved GM lines because of their disruptive effects on trade, as well as increased food and environment safety concerns (HolstJensen 2008) because of the lack of risk assessment. Hence, these incidents are further described.

\section{GM Rice}

Two unauthorised GM contamination cases account for 128 of the 133 rice incidents on the Register. These are "LLRICE" from the United States and "Bt63 rice" from China.

In April 2005, Greenpeace announced that they had evidence of illegal sales and cultivation of unauthorised GM rice in the Hubei province of China (Greenpeace 2005; Zi 2005). Field trials of insect resistant GM rice Bt63 had been carried out in this province for a number of years (Tu et al. 2000, Huang et al. 2005). In 2006, GM rice continued to contaminate food products in China, including baby foods produced by Heinz (Greenpeace 2006a). Bt63 also started to be detected in Europe, with Greenpeace, Friends of the Earth and European governments announcing it had been identified in imported products in Austria, France, UK and Germany. This led to 5 recorded incidents on the Register for 2006 (Figure 5). In 2007, the contamination was also identified in products imported into further countries with reports coming from Japan, Cyprus, Germany, Greece, Italy, Sweden and the UK.

In 2008, the EU Commission announced emergency controls on all rice products from China to prevent imports of unauthorised GM rice (EC 2008, Huggett 2008) with further measures imposed 3 years later (EC 2011). These restrictions require consignments to be certified as not containing GM rice and imports to be subjected to sampling and document checks at the EU port of entry. Although Figure 5 does not show any reduction in GM contamination incidents as a result of these EU measures, it is possible that this is an artefact of increased monitoring, which could have resulted in a greater detection of GM contamination. 


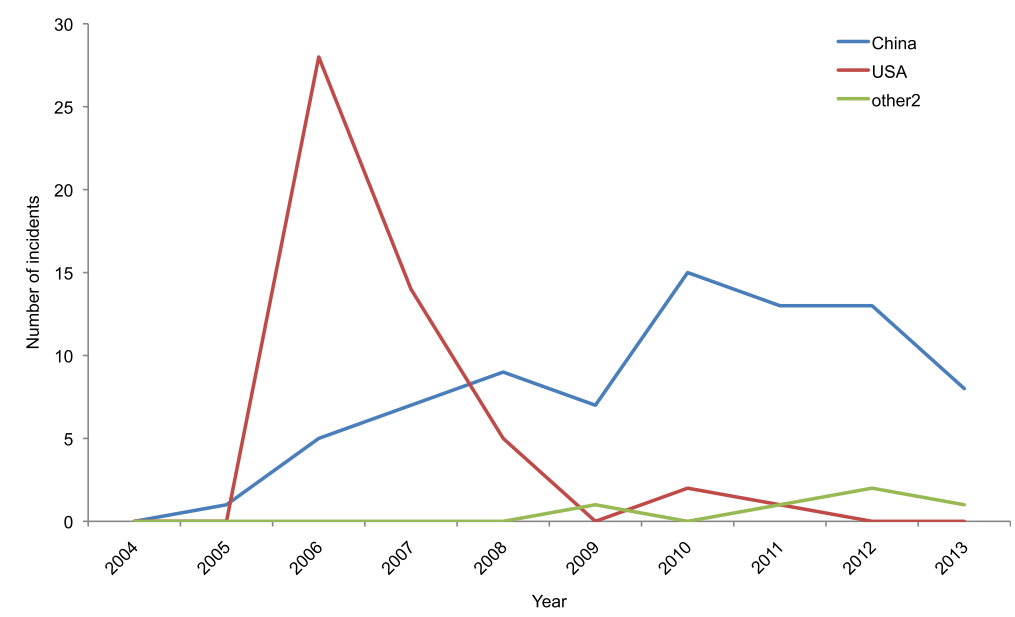

Figure 5 Frequency of GM contamination of rice 2005-2013. Number of incidents recorded on the GM Contamination Register for all countries per year for three unauthorised GM rice cases: US LLRICE; Chinese Bt63 and "other", comprising principally GM contaminated basmati rice either in, or imported from, India and Pakistan.

In the USA, two varieties of glufosinate-tolerant GM rice, LLRICE62 and LLRICE06, were authorised for cultivation and marketing (i.e. afforded deregulated status) in 2000 (Center for Environmental Risk Assessment 2014). These GM varieties have never been grown commercially. A separate glufosinate-tolerant line of GM rice, LL601, was under development by Bayer Crop Science until development (and field trials) ceased in 2001. In August 2006, the 2005 crop of (non-GM) rice in the USA was contaminated with LLRICE601 (US Food and Drug Administration 2006). Following the announcement, LLRICE601 was given deregulated status in the US (Center for Environmental Risk Assessment 2014). However, at the time of contamination it was unauthorised for cultivation and marketing anywhere the in the world. Further, in March 2007, the United States Department of Agriculture (USDA) confirmed that rice line had become contaminated with yet another unauthorised GM rice line LLRICE604, also developed by Bayer Crop Science (USDA 2007). However, LL604 does not appear to have caused as widespread contamination as LL601.

The Register data show how, following the initial announcement in the USA, LLRICE (predominantly LL601) was discovered in 28 countries around the world including EU member states, Sierra Leone, Ghana, Philippines, Kuwait, Mexico and United Arab Emirates, all during 2006. The following 3 years show a rapid fall off rate (Figure 5) but despite this, 6 years elapsed from discovery of the contamination to the last recorded case in 2011.

The two cases of GM rice contamination both caused disruption to international trade but have different histories of contamination rates (Figure 5). Chinese Bt63 continues to be detected in EU imports from its initial discovery in 2005 through to 2013. US LLRICE, however, saw a rapid decline in incidents from 2006-2009 with few cases after this date. This may possibly represent an ease of halting the GM contamination and/or differing monitoring regimes, although these data do not allow further speculation.

There are 5 incidents of GM contamination of rice other than LLRICE and Bt63 (Figure 5). Of these, 4 incidents relate to GM contaminated basmati rice either in, or imported from, India and Pakistan and 1 relates to GM contaminated animal feed imported from the USA.

\section{GM grass}

Between 1999 and 2005, Scotts company conducted field trials of GM creeping bentgrass (Agrostis stolonifera), tolerant to the herbicide glyphosate in the USA. However, the USA Animal and Plant Health Inspection Service (APHIS) found that the company failed to prevent escape of the GM grass during 2003 (US APHIS 2004) and had failed to remove immature seed heads in 2005 (US APHIS 2007a). Gene flow from GM bentgrass can occur over large distances and has been detected over $21 \mathrm{~km}$ from source (Watrud et al. 2004). The GM bentgrass was found to have established in non agronomic habitats up to $3.8 \mathrm{~km}$ away from an Oregon field test site (Reichman et al. 2006). GM bentgrass remains present in uncultivated habitats in Oregon (Charles 2011) and has hybridised with a naturalised grass species (Zapiola and Mallory-Smith 2012). This is an ongoing case of GM contamination and, because of the nature of grass pollen and seeds, it may prove difficult to contain and eradicate (Reichman et al. 2006, Charles 2011).

\section{Pharmaceutical-producing GM crops}

In 2001, ProdiGene conducted field trials in Iowa, USA of GM maize producing a vaccine against a pig disease. In September 2002, government inspectors discovered 
volunteer maize plants growing in a soybean field that was used as a test site for the experimental GM maize in 2001 (US APHIS 2002). Additionally, because the GM maize volunteers may have pollinated neighbouring commercial maize fields, all maize seed and plant material within $1,320 \mathrm{ft}(400 \mathrm{~m})$ of the previous year's test plot was destroyed (US APHIS 2002). At a second site in the same year, APHIS destroyed 500,000 bushels (estimated value US\$2.7 million) after soya from a field containing volunteer GM maize was harvested and mixed with other soya (US APHIS 2002).

In 2004, volunteer GM pharmaceutical corn was again found growing and flowering within the fallow zone surrounding a field trial site and in a nearby sorghum field. The company destroyed all maize volunteers within the 1 mile $(1,610 \mathrm{~m})$ isolation zone, and to plough under the sorghum field (US APHIS 2007b).

A further incident of contamination involving pharmaceutical-producing GM crops occurred in March 2008. The Belgium competent authorities notified the EC RASFF that traces of a protein derived from unauthorised GM Arabidopsis thaliana in a food supplement. The transgenic protein was intended to be used in the measurement of vitamin B12 in laboratory medicine (Bor et al. 2003), and not intended as a food supplement. The product had been imported into Belgium from Denmark.

\section{GM Papaya}

Several different lines of GM papaya resistant to papaya ringspot virus (PRSV) have been under development in tropical regions. However, only two have been authorised for commercial growing, both in the USA (Center for Environmental Risk Assessment 2014). A total of 18 cases of GM contamination have, however, been recorded on the Register. These relate to contamination arising from the development of GM papaya resistant to PRSV in Taiwan and Thailand. Papaya is a widely grown in these two countries, both domestically and for export. Neither country has ever authorised GM papaya for cultivation.

In 2003, GM papaya resistant to PRSV was discovered growing on Taiwanese farms and for sale in local market places (Yu-Tzu 2003). Japan halted Taiwanese papaya imports and the Taiwanese government imposed a ban on GM papaya. The government warned that anyone found growing or selling such fruits could face a fine, and reiterated this warning in 2006 (Taiwan News 2006). The origin of the experimental GM papaya is thought to be government agricultural laboratories developing GM papaya resistant to PRSV.

A similar case of GM papaya contamination arose in Thailand. GM papaya has not been authorised for cultivation in Thailand. In 2004, however, Thai government officials confirmed a Greenpeace finding of the presence of GM papaya in famers' fields (Davidson 2008). A government research station had been developing GM papaya resistant to PRSV, including conducting field trials, but was also selling (non-GM) seed to farmers. Government testing found a sample of sold seed which contained GM papaya. This selling of GM contaminated seed is thought to be the source of the contamination (Davidson 2008). 85 north-eastern farmers were found to have inadvertently grown GM papaya in 2004 (Greenpeace $2006 \mathrm{~b})$ when the government ordered the destruction of all GM papaya plants, including the field trial. In 2005, GM papaya was found in more regions of Thailand (Greenpeace 2006b).

GM papaya was also detected in Thai exports of papaya. The Register records 11 RASFF alerts for GM papaya entering the EU since 2007, with 4 incidents recorded in 2012, and 12 in 2013. GM contamination in Thai papaya appears to be either ongoing. With the exception of Japan, no countries outwith RASFF have reported GM contamination from Thai papaya imports but it is not clear what, if any, inspection regimes exist.

\section{GM Maize Bt10}

The first case of an unauthorised GM line contaminating international food supplies was recorded in 2005. Syngenta had produced two types GM maize lines, Bt10 and Bt11 with two traits, insect-resistance and herbicide tolerance. Only one - Bt11 maize - was eventually commercialised. However, Syngenta's quality control systems had apparently failed to detect Bt10 seeds had been contaminating commercial stocks of Bt11 for 4 years prior to the discovery (Macilwain 2005). Despite this, the case gave rise to only 4 incidents on the Register, primarily because the EU commission made a report on behalf of the whole of the EU. No incidents are recorded for Bt10 contamination beyond 2005.

\section{GM Linseed (Flax)}

GM linseed (or flax) line FP967, named "Triffid", was developed by a public research institution in Canada. It was authorised for commercial use in both Canada and the United States in the late 1990's. However, Triffid GM seed was never sold for commercial production and, in 2001, Triffid was de-registered and it was believed that all known stocks had been identified and destroyed (Canadian Grain Commission 2010, Ellstrand 2012).

In September 2009, Germany found unauthorised genetic material in linseed imported from Canada (EC RASFF 2009), which was subsequently confirmed as Triffid. This led to further testing for GM contamination of linseed and in 2009 the Register recorded a total of 16 incidents in Canada and 15 in the RASFF countries. In 2010, there were 8 incidents recorded on 
the RASFF and a further one recorded in 2011. Positive test results were found in Canada 2009-2011. The levels of GM contamination were reported as falling during these years (Franz-Warkentin 2011) and ongoing efforts include encouraging producers to grow only licenced flax varieties that are free of GM contamination (Flax Council of Canada 2014).

\section{GM wheat}

One case of GM wheat contamination has been reported (Table 1). In 2013, an Oregon farmer noticed that some volunteer wheat did not die-back as expected when sprayed with glyphosate. Analysis by Oregon State University and the USDA determined these volunteers to be a glyphosate tolerant GM wheat line, MON71800 (USDA 2013). Although MON71800 was passed for food and feed consumption in the USA in 2004 (Center for Environmental Risk Assessment 2014), it is included here as the development of the GM wheat line was discontinued in 2004 (Monsanto 2004) and the application for commercialisation (deregulation) was withdrawn. Exports of wheat from the USA where disrupted whilst testing took place (USDA 2013), but no detection of GM wheat has been reported by importer countries. To date, the route of this contamination is unknown but it appears to be an isolated incident.

\section{GM animals}

The Register records 4 incidents (one per year 20012005) where experimental GM pigs have entered into the food or feed supply unauthorised. These are either accidentally comingled with non-GM livestock at the abattoir, sometimes due to mislabelling or, in one case, deliberately stolen (Westphal 2001). Rather than an environmental release, these are an unauthorised entry of a GMO into food or feed. No incidents of contamination of GM fish or insects have been recorded on the Register to date. On the whole, terrestrial GM livestock are considered less prone to escape and establishment of feral populations than GM fish or insects (National Research Council 2004). Especially, experimental GM livestock tend to be kept in animal houses, rarely allowed into an open environment and each individual is tagged and monitored. However, these cases suggest that these too can cause GM contamination.

\section{Detection and monitoring of GM contamination}

The Register records only reported and/or verified incidents of GM contamination. As such, the Register does not represent all contamination incidents that have taken place globally. There are undoubtedly other GM contamination incidents that remain undetected or unreported. This could be because it is not possible to detect the GMO, that monitoring for GM contamination either does not take place or is insufficient to detect all or many GM contamination incidents and/or that GM contamination is not reported.

The RASFF is the only database which systematically records GM contamination events but is only for the EU region. The high number of incidents documented on the Register from RASFF (approximately 60\% of the total) demonstrates its effectiveness. Nevertheless, the RASFF database is the product of national monitoring, and dependent on the effectiveness of national monitoring regimes for monitoring GM contamination. The high number of events recorded by the RASFF countries of Germany, France and United Kingdom may reflect more efficient monitoring programmes, rather than a high number of products or imports containing unapproved GMOs.

GMO detection relies on the establishment of an analytical methodology specific to that GMO, e.g. the PCR methodologies collated by the EC JRC (EC JRC 2010, 2014a). Any contamination by unauthorised GMOs, such as those in experimental field trials, may not be readily detectable, as most (if not all) national regulatory authorities do not require companies to submit an analytical methodology for detection of the test GM crop when seeking approval for field trials. The lack of an analytical methodology can make detection of GM contamination extremely difficult, if not impossible. PCR screening for elements that are common to many GM crops (e.g. the cauliflower mosaic virus promoter, CaMV 35S) can indicate of whether GM material is present. However, it does not allow identification of the gene that confers the trait, which is necessary to identify the specific GM line. For example, whilst detection methodologies are now available for both LLRICE and Chinese Bt63 (EC JRC 2014a), these were not available until after the GM contamination had been reported. For the cases of pharmaceutical-producing GM crops, no detection methodology is available. Thus, it would not be possible for any third party to monitor for the presence/absence of these GM crops in subsequent crop harvests, if contamination was suspected.

The Register reports cases of contamination from unauthorised GM crops. These cases include LLRICE, Bt63 rice, grass, pharmaceutical maize, papaya, and Bt10 maize all of which were at the research or development stage, and Triffid linseed and wheat which had undergone some safety assessment, but were not authorised for cultivation. These nine cases clearly show that GM contamination can occur independently of commercialisation, e.g. escapes from field trials or illegal plantings.

Once a GM contamination incident has been detected, this often leads to monitoring specifically for the associated GM line and can result in a high number of incidents immediately after the initial discovery (e.g. LLRICE). This can lead to a sharp increase in the number of contamination 
incidents per year for that crop, e.g. as seen for rice in 2006/7. The pattern of GM contamination incidents varies a great deal between cases. For example, the cases of Bt10 and all pharmaceutical GM crops cases only extend over a year. Starlink, LLRICE and FP967 flax show a sharp decrease after $2 / 3$ years but with ongoing isolated incidents of GM contamination. It is not clear why some cases of contamination fall rapidly and others not so rapidly. Governments and trading bodies wish reduce any economic impact from GM contamination as soon as possible. In some cases at least, this has evidently spurred governments and companies to make efforts to eliminate contamination, such as the destruction of GM papaya in Thailand, or licensing GM-free flax varieties. Internationally-traded commodity crops, therefore, are likely to receive the most efforts to reduce GM contamination.

The seed supply system is a factor in determining the persistence of GM contamination. GM contamination of maize landraces in Mexico may be difficult to eradicate because these varieties are dominantly open-pollinated, where seed is saved from harvest for next year's planting. The GM traits could even introgress through these populations (Dyer et al. 2009). In contrast, hybrid seed systems are more centrally controlled. Hybrid seed is purchased each year and hybrid seeds are produced via crossing of specified varieties. This allows the testing of the parental varieties for the absence GM material prior to breeding, each year if necessary.

GM grass in the western USA could represent the first case where a GM crop has entered into wild or naturalized populations, and it remains to be seen whether it will introgress through those populations.

\section{Routes of GM contamination}

Many cases of GM contamination are not investigated, but those from unauthorised events have been investigated the most. Cross pollination is not the sole route of GM contamination. A number of routes have been identified including escape of seeds (grass), illegal plantings (Bt63 rice), incorrect labelling (pigs) and volunteers from previous year's crops have all been identified as the cause of GM contamination. It's also possible that a GM contamination case arises from two or more routes. Often, the route of GM contamination is not clear. For example, Bayer was unable to identify the route of contamination responsible for the LLRICE case, calling it "an act of God" (Weiss 2006).

Finally, it is beyond the scope of the Register or this paper to speculate about health or environmental implications from these specific contamination cases. However, if GMOs that have not undergone any food/feed or environmental risk assessments enter the food/feed chain or environment, this gives regulators cause for concern.

\section{Conclusions}

Nearly 400 incidents of GM contamination have been recorded on the Register since 1997. There does not appear to be an overall pattern relating to any one particular factor. Instead, factors could include, but may not be limited to global acreage, international trade, plant biology and monitoring frequency. Experimental GM livestock have, on occasion, entered either human food or animal feed.

All three principal, commercially grown GM food and feed crops (oilseed rape, soya and maize) have been associated with GM contamination incidents over the past 17 years. There have also been nine cases of contamination associated with GM lines with no authorisation for cultivation anywhere in the world, mostly at the research and development stage. An important conclusion of this work is that GM contamination can occur independently of commercialisation. Indeed, GM lines of rice, the crop associated with the highest number of incidents, has never been grown commercially. The detection of GMO contamination is dependent on both routine and targeted monitoring regimes, which appears to be inconsistent from country to country, even within the EU. The lack of an analytical methodology for the detection of GM crops at the field trial stage (i.e. precommercialisation) can hamper efforts to detect any contamination arising from such GM lines.

\section{Additional file}

Additional file 1: GM contamination database - analysis.xlsb.

\section{Abbreviations}

APHIS: Animal and Plant Health Inspection Service; DNA: Deoxyribonucleic acid; EC: European commission; ELISA: Enzyme-Linked Immunosorbent Assay; EU: European Union; EPA: Environmental Protection Agency; GM: Genetically modified; GMO: Genetically modified organism; ISO: International organisation for standardization; JRC: Joint research centre; LL: Liberty link; NGO: Non-governmental organisation; PRSV: Papaya ringspot virus; PCR: Polymerase chain reaction; RASFF: Rapid alert system for food and feed; UN: United Nations; USA: United States of America; USDA: United States Department of Agriculture.

\section{Competing interests}

Neither author has competing financial interests although both authors are employed by NGOs which oppose the environmental release of GM crops.

\section{Authors' contributions}

The GM Contamination Register is maintained by B.Price and part funded by Greenpeace. Both authors contributed equally to the preparation of this manuscript. Both authors read and approved the final manuscript.

\section{Author details}

'Consultant for GeneWatch UK, 60 Lightwood Road, Buxton SK17 7BB, UK. ${ }^{2}$ Greenpeace Resaerch Laboratories, Innovation Centre Phase 2, University of Exeter, Exeter EX4 4RN, UK.

Received: 22 May 2014 Accepted: 26 September 2014

Published online: 25 October 2014 


\section{References}

Bauer-Panskus A, Breckling B, Hamberger S, Then C (2013) Cultivation-independent establishment of genetically engineered plants in natural populations: current evidence and implications for EU regulation. Environ Sci Eur 25:34. doi:10.1186/ 2190-4715-25-34

Bor MV, Fedosov SN, Laursen NB, Nexø E (2003) Recombinant human intrinsic factor expressed in plants is suitable for use in measurement of vitamin B12. Clin Chem 49:2081-2083

Bucchini L, Goldman LR (2002) Starlink corn: a risk analysis. Environ Health Perspect 110:5-13

Canadian Grain Commission (2010) Background information on genetically modified material found in Canadian flaxseed. www.grainscanada.gc.ca/ gmflax-lingm/pfsb-plcc-eng.htm. Accessed 14 May 2014

Center for Environmental Risk Assessment (2014) GM Crop Database. Center for Environmental Risk Assessment (CERA). ILSI Research Foundation, Washington D.C. http://cera-gmc.org/GMCropDatabase. Accessed 14 May 2014

Charles D (2011) Scientist in the middle of the GM-Organic Wars. Science 332:168

Dalton R (2008) Modified genes spread to local maize. Nature 456:149

Davidson SN (2008) Forbidden fruit: transgenic papaya in Thailand. Plant Physiol 147:487-493

Dyer GA, Serratos-Hernández JA, Perales HR, Gepts P, Piñeyro-Nelson A, Chávez A, Salinas-Arreortua N, Yúnez-Naude A, Taylor JE, Alvarez-Buylla ER (2009) Dispersal of transgenes through maize seed systems in Mexico. PLoS One 4:e5734

Eastham K, Sweet J (2002) Genetically Modified Organisms (GMOs): the Significance of Gene Flow Through Pollen Transfer. Expert's Corner Series. European Environment Agency, Copenhagen. http://www.eea.europa.eu/ publications/environmental_issue_report_2002_28 Accessed 14 May 2104

EC (2003) Regulation (EC) No 1829/2003 of the European Parliament and of the Council of 22 September 2003 on genetically modified food and feed. O J Eur Union L 268:1-23

EC (2008) Commission requires certification for Chinese rice products to stop unauthorised GMO from entering the EU. http://europa.eu/rapid/pressReleases Action.do? reference $=\mid \mathrm{P} / 08 / 219 \&$ type $=H T M L$ \&aged $=0$ \&language $=E N \&$ guilanguage=en. Accessed 14 May 2014

EC (2011) EC O J Eur Union L 343:140-147

EC (2013) EU rice trade 2012/13. http://ec.europa.eu/agriculture/cereals/trade/ rice/2012-13_en.pdf. Accessed 14 May 2014

EC (2014a) EU Register of authorised GMOs. http://ec.europa.eu/food/dyna/ gm_register/index_en.cfm. Accessed 18 Sept 2014

EC (2014b) Deliberate release into the environment of GMOs for any other purposes than placing on the market (experimental releases). http://gmoinfo. jrc.ec.europa.eu/. Accessed 18 Sept 2014

EC JRC (2010) Compendium of reference methods for GMO analysis. http://ihcp. jrc.ec.europa.eu/our_activities/gmo/gmo_analysis/compendium-referencemethods-gmo-analysis. Accessed 18 Sept 2014

EC JRC (2014a) GMO Methods: EU Database of Reference Methods for GMO Analysis. http://gmo-crl.jrc.ec.europa.eu/gmomethods/. Accessed 14 May 2014

EC JRC (2014b) GMO Capacity Building. http://ihcp.jrc.ec.europa.eu/our_activities/ gmo/gmo_capacity_building. Accessed 18 Sept 2014

EC RASFF (2009) Notification detail - 2009.1171. https://webgate.ec.europa.eu/ rasff-window/portal/index.cfm?event=notificationDetail\&NOTIF_REFERENCE $=2009.1171$ Accessed 14 May 2014

EC RASFF (2014) Rapid Alert System for Food and Feed (RASFF). http://ec.europa. eu/food/food/rapidalert/index_en.htm. Accessed 14 May 2014

Ellstrand NC (2012) Over a Decade of Crop Transgenes out-of-Place. In: Wozniak CA, McHughen A (ed) Regulation of Agricultural Biotechnology: The United States and Canada. Springer, London

Elsanhoty RM, Al-Turki Al, Ramadan MF (2013) Prevalence of genetically modified rice, maize, and soy in Saudi food products. Appl Biochem Biotechnol 171:883-899

Ermolli M, Fantozzi A, Marini M, Scotti D, Balla B, Hoffmann S, Querci M, Paoletti C, van den Eede G (2006) Food safety: screening tests used to detect and quantify GMO proteins. Accred Qual Assur 11:55-57

Flax Council of Canada (2014) GM Flax Update January 18 2014. http:// flaxcouncil.ca/files/web/NEWS\%20RELEASE\%20-\%20Flax\%20Council\%20of\% 20Canada\%20Urges\%20Producers\%20to\%20Declare\%20Unlicensed\%20Flax\% 20Varieties\%20-\%2001.28.14.pdf. Accessed 14 May 2014

Fox JL (2001) EPA re-evaluates StarLink license. Nat Biotechnol 19:11

Franz-Warkentin P (2011) Flax Industry Sees "Good Progress" Against Triffid. Manitobar Co-operator, Canada. http://www.manitobacooperator.ca/daily/ flax-industry-sees-good-progress-against-triffid-2. Accessed 14 May 2014
Genetic Rights Foundation (2012) Illegal field trials of GM cherry, kiwi and olive trees exposed in Italy by the Genetic Rights Foundation. http://www. fondazionedirittigenetici.org/fondazione/en/displaynews_en.php?id=19. Accessed 14 May 2014

GM Contamination Register (2014). http://www.gmcontaminationregister.org Accessed 14 May 2014

Greenpeace (2005) Greenpeace discovers illegal GE rice in China. http://www. greenpeace.org/international/en/news/features/scandal-greenpeace-exposesil/. Accessed 14 May 2014

Greenpeace (2006a) Illegal genetically engineered rice found in Heinz baby food in China. http://www.greenpeace.org/eastasia/press/releases/20060314-heinzrice-cereal/ Accessed 14

Greenpeace (2006b) Contamination by genetically engineered papaya in Thailand. http://www.greenpeace.org/international/Global/international/ planet-2/report/2006/6/GEpapayaThailand.pdf. Accessed 14 May 2014

Greenpeace (2009) Des pollens transgéniques dans le miel d'importation. http:// www.greenpeace.org/switzerland/fr/publications/actualites/agriculture/ pollens-transgeniques-miel/ Accessed 14

Holst-Jensen A (2008) GMO testing - trade, labeling or safety first? Nat Biotechnol 26:858-859

Huang J, Hu R, Rozelle S, Pray C (2005) Insect resistant GM rice in farmers' fields: assessing productivity and health effects in China. Science 308:688-690

Huggett B (2008) EU to monitor for Chinese GM rice. Nat Biotechnol 26:478

Information Systems for Biotechnology (2014) USDA Field Tests of GM Crops. http://www.isb.vt.edu/search-release-data.aspx. Accessed 17 Sept 2014

International Foundation for Organic Agriculture Movements (2002) Position on genetic engineering and genetically modified organisms. http://www.ifoam. org/en/position-genetic-engineering-and-genetically-modified-organisms. Accessed 14 May 2014

International Service for the Acquisition of Agri-biotech Applications (2013) Brief 46: Executive Summary. Global Status of Commercialized Biotech/GM Crops: 2013. http://www.isaaa.org/resources/publications/briefs/46/executivesummary/default.asp Accessed 14 May 2014

ISO (2005) ISO/IEC 17025:2005 General requirements for the competence of testing and calibration laboratories. http://www.iso.org/iso/catalogue_detail. htm?csnumber=39883. Accessed 18 Sept 2014

Macilwain C (2005) US launches probe into sales of unapproved transgenic corn. Nature 434:423

Marvier M, van Acker RC (2005) Can crop transgenes be kept on a leash? Front Ecol Environ 3:92-100

Mellon M, Rissler J (2004) Gone to Seed: Transgenic Contaminants in the Traditional Seed Supply. Union of Concerned Scientists. http://www.ucsusa. org/food_and_agriculture/our-failing-food-system/genetic-engineering/goneto-seed.html. Accessed 18 Sept 2014

Meridian Institute (2002) Illegal Genetically Engineered Starlink Corn Contaminates Food Aid. http://www.merid.org/Content/News_Services/ Food_Security_and_AgBiotech_News/Articles/2002/06/11/ Illegal_Genetically_Engineered_Starlink_Corn_Contaminates_Food_Aid.aspx. Accessed 16 Oct 2014

Miraglia M, Berdal KG, Brera C, Corbisier P, Holst-Jensen A, Kok EJ, Marvin HJP, Schimmel H, Rentsch J, van Rie JPPF, Zagon J (2004) Detection and traceability of genetically modified organisms in the food production chain. Food Chem Toxicol 42:1157-1180

Monsanto (2004) Monsanto to realign research portfolio, development of roundup ready wheat deferred. http://news.monsanto.com/press-release/ monsanto-realign-research-portfolio-development-roundup-ready-wheatdeferred. Accessed 18 Sept 2014

National Research Council (2004) Bioconfinement of animals: fish, shellfish, and insects. In: Biological confinement of genetically engineered organisms. US National Academies Press, Washington DC, pp 130-158

Office of the Gene Technology Regulator (2014) Genetically modified organisms field trial sites. Department of Health, Australian Government. http://www. ogtr.gov.au/internet/ogtr/publishing.nsf/content/map. Accessed 18 Sept 2014

Ortiz-Garcia S, Ezcurra E, Schoel B, Acevedo F, Soberon J, Snow AA (2005) Absence of detectable transgenes in local landraces of maize in Oaxaca, Mexico (2003-2004). Proc Natl Acad Sci U S A 102:12338-12343

Piñeyro-Nelson A, Van Heerwaarden J, Perales HR, Serratos-Hernández JA, Rangel A, Hufford MB, Gepts P, Garay-Arroyo A, Rivera-Bustamante R, Alvarez-Buylla ER (2009) Transgenes in Mexican maize: molecular evidence and methodological considerations for GMO detection in landrace populations. Mol Ecol 18:750-761 
Quist D, Chapela I (2001) Transgenic DNA introgressed into traditional maize landraces in Oaxaca, Mexico. Nature 414:541-543

Reichman JR, Watrud LS, Lee EH, Burdick CA, Bollman MA, Storm MA, King GA, Mallory-Smith C (2006) Establishment of transgenic herbicide-resistant creeping bentgrass (Agrostis stolonifera L.) in nonagronomic habitats. Mol Ecol 15:4243-4255

Rong J, Lu B-R, Song Z, Su J, Snow AA, Zhang X, Sun S, Chen R, Wang F (2007) Dramatic reduction of crop-to-crop gene flow within a short distance from transgenic rice fields. New Phytol 173:346-353

Samuels J (2013) Transgene flow from Bt brinjal: a real risk? Trends Biotechnol 31:333-334

Snow A (2009) Unwanted transgenes re-discovered in Oaxacan maize. Mol Ecol 18:569-571

Snow AA, Pilson D, Riesberg LH, Paulsen MJ, Pleskac N, Reagon MR, Wolf DE, Selbo SM (2003) A Bt transgene reduces herbivory and enhances fecundity in wild sunflower. Ecol Appl 13:279-86

Taiwan News (2006) Genetically modified papaya said unsafe. http://www. taiwannews.com.tw/etn/news_content.php?id=105252. Accessed 14 May 2014

Tu J, Zhang G, Datta K, Xu C, He Y, Zhang O, Khush G, Datta SK (2000) Field performance of transgenic elite commercial hybrid rice expressing Bacillus thuringiensis delta-endotoxin. Nat Biotechnol 18:1101-1104

UN Cartagena Protocol on Biosafety (2014). http://bch.cbd.int/protocol/ Accessed 14 May 2014

US APHIS (2002) Noncompliance history: ProdiGene. http://www.aphis.usda.gov/ wps/portal/aphis/resources/enforcement-actions?1 dmy\&urile=wcm\%3apath\% 3a\%2Faphis_content_library\%2Fsa_our_focus\%2Fsa_biotechnology\% 2Fsa_compliance_and_inspections\%2Fct_compliance_history. Accessed 14 May 2014

US APHIS (2004) Noncompliance history: The Scotts Company. http://www.aphis. usda.gov/wps/portal/aphis/resources/enforcement-actions?1 dmy\&urile=wcm \%3apath\%3a\%2Faphis_content_library\%2Fsa_our_focus\%2Fsa_ biotechnology\%2Fsa_compliance_and_inspections\%2Fct_compliance_ history. Accessed 14 May 2014

US APHIS (2007a) Noncompliance history: The Scotts Company LLC. http://www. aphis.usda.gov/wps/portal/aphis/resources/enforcement-actions? 1 dmy\&urile=wcm\%3apath\%3a\%2Faphis_content_library\%2Fsa_our_focus\% 2Fsa_biotechnology\%2Fsa_compliance_and_inspections\%2Fct_compliance_ history. Accessed 14 May 2014

US APHIS (2007b) Noncompliance history: ProdiGene. http://www.aphis.usda.gov/ wps/portal/aphis/resources/enforcement-actions?1 dmy\&urile=wcm\%3apath\% 3a\%2Faphis_content_library\%2Fsa_our_focus\%2Fsa_biotechnology\% 2Fsa_compliance_and_inspections\%2Fct_compliance_history. Accessed 14 May 2014

US Environmental Protection Agency (2008) Starlink ${ }^{\text {TM }}$ Corn Regulatory Information. http://www.epa.gov/pesticides/biopesticides/pips/starlink_corn. htm. Accessed 14 May 2014

US Food and Drug Administration (2006) Statement on report of bioengineered rice in the food supply. http://www.fda.gov/Food/FoodScienceResearch/ Biotechnology/Announcements/ucm109411.htm. Accessed 14 May 2014

USDA (2007) Report of LibertyLink Rice Incidents. http://www.aphis.usda.gov/ newsroom/content/2007/10/content/printable/RiceReport10-2007.pdf. Accessed 14 May 2014

USDA (2013) Release No. 0127.13: Statement on the Detection of Genetically Engineered Wheat in Oregon. http://www.usda.gov/wps/portal/usda/ usdahome?contentid=2013/06/0127.xml. Accessed 19 September 2014

USDA Economic Research Service (2014) Adoption of genetically engineered crops in the US. http://www.ers.usda.gov/publications/err-economic-researchreport/err162.aspx. Accessed 14 May 2014

Watrud LS, Lee EH, Fairbrother A, Burdick C, Reichman JR, Bollman M, Storm M, King GJ, Van de Water PK (2004) Evidence for landscape-level, pollen mediated gene flow from genetically modified creeping bentgrass with CP4 EPSPS as a marker. Proc Natl Acad Sci U S A 101:14533-14538

Weiss R (2006) Firm Blames Farmers, 'Act of God' for Rice Contamination. Washington Post, USA. http://www.washingtonpost.com/wp-dyn/content/ article/2006/11/21/AR2006112101265.html. Accessed 14 May 2014

Westphal SP (2001) Pig out. New Sci 2301:14. http://www.newscientist.com/ article/mg17123011.700-pig-out.html\#.U3Ec9690X50. Accessed 14 May 2014

Yu-Tzu C (2003) Concern Over GM Papayas Raised by Jao. Taipei Times, Taiwan. http://www.taipeitimes.com/News/taiwan/archives/2003/09/16/2003068021. Accessed 14 May 2014
Zapiola ML, Mallory-Smith CA (2012) Crossing the divide: gene flow produces intergeneric hybrid in feral transgenic creeping bentgrass population. Mol Ecol 21:4672-4680

Zi X (2005) GM rice forges ahead in China amid concerns of illegal planting. Nat Biotechnol 23:637

\section{doi:10.1186/s40550-014-0005-8}

Cite this article as: Price and Cotter: The GM Contamination Register: a review of recorded contamination incidents associated with genetically modified organisms (GMOs), 1997-2013. International Journal of Food Contamination 2014 1:5.

\section{Submit your manuscript to a SpringerOpen ${ }^{\odot}$ journal and benefit from:}

- Convenient online submission

- Rigorous peer review

- Immediate publication on acceptance

- Open access: articles freely available online

- High visibility within the field

- Retaining the copyright to your article

Submit your next manuscript at $\gg$ springeropen.com 